\title{
Índice de área foliar e produtividade do tomate sob condições de ambiente protegido ${ }^{1}$
}

\author{
Ligia S. Reis ${ }^{2}$, Carlos A. V. de Azevedo ${ }^{3}$, Abel W. Albuquerque ${ }^{2} \&$ Josué F. S. Junior $^{4}$
}

\section{RESUMO}

O cultivo de tomate tem-se expandido nos últimos anos em ambiente protegido, especialmente nas regiões Sul e Sudeste do Brasil, com o propósito de melhorar a produtividade e a qualidade dos produtos agrícolas, em razão de oferecer regularidade na produção. Objetivou-se, com o presente trabalho, determinar, ao longo do ciclo da cultura, a relação entre o índice de área foliar e a produtividade e, ao final do ciclo, os componentes de produção do tomateiro, em ambiente protegido. Os modelos foram gerados por meio de equações polinomiais de $1^{\mathrm{a}}$ e $2^{\mathrm{a}}$ ordem tendo-se, como variável independente, o número de dias após o transplantio. Constatou-se ser possível determinar, em ambiente protegido e por meio de modelo matemático, o índice de área foliar dessa olerícola considerando-se os dias após o transplantio. A partir de valores de índice de área foliar pode-se determinar a produtividade da cultura e o período da máxima produtividade auxiliando os agricultores a estimar a melhor época de semeadura e o transplante do tomateiro.

Palavras-chave: modelos, variáveis climáticas, manejo cultural, Lycopersicon esculentum

\section{Leaf area index and productivity of tomatoes under greenhouse conditions}

\begin{abstract}
The tomato cultivation in the greenhouse has been expanded in the last years, mainly, in the South and Southeast regions of Brazil, whose purpose is to improve the productivity and the quality of the agricultural products, offering regularity in the production. The present study aimed to determine, along the crop cycle, the relationship between the leaf area index and the productivity, and at the end of the cycle, the components of production of the tomato in the greenhouse. The models were generated through polynomial equations of $1^{\text {st }}$ and $2^{\text {nd }}$ order, having as independent variable the number of days after the transplanting. It was verified that it is possible to determine, in the greenhouse, through mathematical models, the leaf area index of the tomato crop considering the days after the transplanting. Basing on values of leaf area index, the productivity of the crop and the period of the maximum productivity can be determined, aiding the farmers to determine the best sowing and transplanting time of the tomato crop.
\end{abstract}

Key words: models, weather variables, crop management, Lycopersicon esculentum 


\section{INTRODUÇÃO}

O propósito do cultivo em ambiente protegido é melhorar a produtividade e a qualidade dos produtos agrícolas por oferecer regularidade na produção (Carvalho \& Tessarioli Neto, 2005).

Essa técnica permite proteção às plantas contra temperaturas elevadas e alta intensidade de radiação solar, durante todo o seu crescimento. A luz tem influência complexa no crescimento, no desenvolvimento e na produção das culturas e, devido à absorção e reflexão do material da cobertura plástica, a densidade de fluxo da radiação solar global no interior do ambiente protegido, é menor que a observada externamente.

O aumento da irradiância pode elevar a produção de fotoassimilados e sua disponibilidade para o crescimento da planta e produção de frutos. Entretanto, quando a radiação solar é excessivamente elevada pode haver aumento na taxa transpiratória da planta, resultando em fechamento estomático e na diminuição da fotossíntese (Andriolo, 2000). A temperatura é fator limitante para o cultivo do tomateiro em estufa em que a máxima permitida é $30^{\circ} \mathrm{C}$ e a mínima, $12{ }^{\circ} \mathrm{C}$. A planta exige, também, uma termoperiodicidade ao redor de $6{ }^{\circ} \mathrm{C}$ para que ocorra um crescimento vegetativo moderado e desejado (Pereira et al., 2000).

A radiação solar é o elemento ambiental que mais contribui para as flutuações de florescimento e para a formação de frutos. O valor limite de radiação solar estabelecido pela FAO (1990) e que permite, à planta, seu pleno crescimento, é de $8,4 \mathrm{MJ} \mathrm{m}^{-2}$.

Caliman et al. (2005) consideram que a elevação da umidade do ar favorece a expansão foliar do tomateiro contribuindo para a ocorrência de uma interceptação maior de energia luminosa, resultando em também uma produção maior de fotoassimilados nas plantas cultivadas em ambiente protegido e, por conseguinte, maior produção.

A variação do índice de área foliar durante o ciclo de determinada cultura é um dado relevante para determinação da data de semeadura e transplante. As culturas devem ter sua semeadura programada de modo que os valores máximos do índice de área foliar (IAF) coincidam com a época de elevada radiação, quando então a fotossíntese líquida será máxima. A área foliar (AF) e, consequentemente, o índice de área foliar (IAF) são de suma importância para que se possa modelar o crescimento e o desenvolvimento das plantas e, por conseguinte, a produtividade total da cultura. A área foliar de uma planta depende do número e do tamanho das folhas e do seu tempo de permanência na planta, isto é, pode variar ao longo do ciclo da cultura, segundo Monteiro et al. (2005).

Os princípios e as práticas da análise de crescimento têm, como objetivo, descrever e interpretar o desempenho de determinada espécie em ambiente natural ou controlado. Vários índices fisiológicos também são utilizados nessa análise, como índice de área foliar, taxas de crescimento da cultura, de crescimento relativo e de assimilação líquida (Pôrto et al., 2005; Costa et al., 2006; Monte et al., 2009).
O aumento da área foliar propicia um aumento na capacidade da planta de aproveitar a energia solar visando à realização da fotossíntese e, desta forma, pode ser utilizada para avaliar a produtividade; além disto, o IAF pode ser utilizado na estimativa da evapotranspiração e das emissões biogênicas (Gonzalez-Sanpedro et al., 2008). Os modelos matemáticos que estimam a área foliar podem ser obtidos através da correlação entre a largura e o comprimento das folhas, por meio da análise de regressão, porém o método não destrutivo, baseado em medições lineares, tem sido usado por vários autores (Astegiano et al., 2001). A distribuição de matéria seca entre os diferentes órgãos da planta tem papel fundamental na produção de uma cultura. A produção de biomassa é a expressão do aumento irreversível da massa das folhas, caules, frutos e raízes ao longo do tempo, características quantitativas passíveis de serem utilizadas na comparação de cultivares (Fageria et al., 2006) ou genótipos com diferentes objetivos, entre eles, na utilização de diferentes tipos de coberturas do solo.

Rocha (2009) constatou, trabalhando com tomate cereja, que o principal órgão armazenador de matéria seca na cultura do tomateiro, foi a folha. Segundo o autor as folhas, além de fontes principais se caracterizaram também como drenos de fotoassimilados seguidas do caule e, por último, os frutos. Entretanto os frutos, segundo diversos autores (Andriolo et al., 2004; Guimarães et al., 2009), são considerados o dreno principal da planta desde o início da frutificação até a última colheita de frutos maduros, chegando a acumular mais de $50 \%$ do total da matéria seca produzida pela planta.

Ante o exposto objetivou-se, com o presente trabalho, determinar, ao longo do ciclo da cultura, a relação entre o índice de área foliar e a produtividade e, ao final do ciclo, os componentes de produção da cultura do tomate em condições atmosféricas de ambiente protegido.

\section{Material e Métodos}

$\mathrm{O}$ experimento foi conduzido em estufa pertencente à área experimental do Centro de Ciências Agrárias, Universidade Federal de Alagoas, no município de Rio Largo, $9^{\circ} 28^{\prime} \mathrm{S}, 35^{\circ}$ $49^{\prime}$ W, $127 \mathrm{~m}$ de altitude, localizado em áreas de tabuleiros costeiros pertencentes ao Grupo Barreiras. Segundo a classificação de Thorntwaite-Mather, o clima é quente úmido (B1) com deficiência de água moderadamente no verão (s) e grande excesso de água no inverno (w). A precipitação pluvial média anual varia de 1500 a $2000 \mathrm{~mm}$ (Souza et al., 2005).

Foi utilizada estufa com largura de 6,5 e $17,5 \mathrm{~m}$ de comprimento, com cobertura de polietileno $120 \mu$ e sombrite $50 \%$ nas laterais, altura do pé direito de $2 \mathrm{~m}$ e, no arco central, $4 \mathrm{~m}$. O solo da área experimental foi classificado como Latossolo Amarelo Coeso Argissólico, com textura média argilosa, conforme o sistema brasileiro de classificação de solos (EMBRAPA, 1999).

O plantio foi realizado em bandejas de polipropileno e, quando as plantas apresentaram 6 folhas definitivas, foram levadas ao ambiente protegido e transplantadas em espaçamento 
de $0,4 \mathrm{~m}$ entre plantas e 1,0 m entre fileiras, em seis canteiros, com $16 \mathrm{~m}$ de comprimento totalizando 240 plantas.

Realizou-se uma adubação de fundação com biofertilizante (03-12-06 + micros) e torta de mamona (umidade $=8,13 \%$, óleo $=13,10 \%$, proteína bruta $=28,74 \%$, cinzas $=12,11 \%, \mathrm{~N}=60 \%$, $\mathrm{P}=3,0 \%$ e $\mathrm{K}=0,96 \%$ ).

Foram aplicados $10 \mathrm{~g}$ de ureia por planta, aos 15 e 22 dias após o transplantio. A fim de evitar a podridão apical dos frutos aplicaram-se $5 \mathrm{~g}$ por cova de nitrocálcio, por ocasião do transplantio e após trinta dias da primeira aplicação; a irrigação por gotejamento foi realizada a cada dois dias, com um gotejador por planta com vazão de $8 \mathrm{~L} \mathrm{~h}^{-1}$. O manejo da irrigação foi realizado a partir do balanço hídrico obtido nos lisímetros instalados na área os quais, por sua vez, foram confeccionados com fibra de vidro, com 1,0 m de largura e 1,0 $\mathrm{m}$ de comprimento, profundidade de $0,7 \mathrm{~m}$ e $0,6 \mathrm{~m}$ nas outras extremidades, formando um declive entre as extremidades, $\mathrm{o}$ que permitia o escoamento da água. As leituras nos lisímetros indicaram a evapotranspiração diária da cultura (ETc) a qual foi determinada pelo balanço médio de entrada e saída de água, conforme Eq. 1.

$$
\mathrm{ETc}=\mathrm{I}-\mathrm{D}
$$

em que:

I - lâmina de irrigação, $\mathrm{mm}$

D - lâmina drenada no lisímetro, mm

Avaliaram-se, semanalmente e ao longo do ciclo da cultura, a área foliar ( $\mathrm{m}^{2}$ de folha por planta) e o índice de área foliar (IAF) através das seguintes equações:

$$
\mathrm{AF}=\mathrm{CLf}
$$

em que:

$$
\begin{array}{ll}
\text { AF } & \text { - área foliar, } \mathrm{m}^{2} \\
\mathrm{C} & \text { - comprimento da folha, } \mathrm{m} \\
\mathrm{L} & \text { - largura da folha, } \mathrm{m} \\
\mathrm{f} & \text { - fator de forma }(0,59)
\end{array}
$$

$$
\mathrm{IAF}=\frac{(\mathrm{AF} \times \mathrm{NP})}{\mathrm{AT}}
$$

em que:

IAF - índice de área foliar, $\mathrm{m}^{2} \mathrm{~m}^{-2}$

$\mathrm{AF}$ - área foliar média de duas plantas, $\mathrm{m}^{2}$

NP - número de plantas por metro quadrado

AT - área total considerada, $1 \mathrm{~m}^{2}$

A área foliar foi determinada pela medição do comprimento (C) e a largura (L) de todas as folhas das plantas marcadas, em que o comprimento foi definido como a distância entre o ponto de inserção do pecíolo no limbo foliar e a extremidade oposta da folha, enquanto a largura, como a maior dimensão perpendicular ao eixo do comprimento, com fator de forma "f cujo valor encontrado foi $0,59 "$.

Para avaliar o IAF em função do número de dias após o transplantio (DAT) utilizou-se equação polinomial de segunda ordem. Após o início da formação dos frutos efetuaram-se duas colheitas semanais e, a partir da massa total de cada fruto colhido em determinada área, obteve-se a produtividade em $\mathrm{kg}$ $\mathrm{m}^{-2}$ semana $^{-1}$ enquanto ao final do ciclo foram feitas medições da produtividade total $\left(\mathrm{kg} \mathrm{m}^{-2}\right)$, do número de frutos por planta, dos perímetros maior e menor do fruto e do peso de fruto.

No interior da estufa e no campo foram feitas medições nos turnos noturno e diurno dos seguintes parâmetros meteorológicos: temperatura do ar $(\mathrm{T})$, radiação solar global $(\mathrm{Rg})$, saldo de radiação $(\mathrm{Rn})$, velocidade do vento $(\mathrm{Vv})$, umidade relativa do ar (UR) e radiação fotossinteticamente ativa (PAR).

Para medições de temperatura e umidade de ar em dois níveis $\left(Z_{1}\right.$ - altura do dossel e $\left.Z_{2}=2,0 \mathrm{~m}\right)$ instalaram-se dois sensores automáticos, modelo HPM 45C. Com a evolução da altura da cultura os sensores se elevaram de modo que os níveis de medição se mantivessem nas alturas estabelecidas, isto é, sempre acima do dossel. A velocidade do vento foi medida a 2,0 $\mathrm{m}$ do dossel vegetativo, por um anemômetro. Além desses sensores dois piranômetros (CM3, Kipp Zone) foram instalados para medida de radiação solar global e radiação fotossinteticamente ativa (Li-Cor) e um saldo radiômetro (NR LITE, Kipp e Zone) para as medições do saldo de radiação, que foi instalado na área gramada nas condições padrões de ETo.

As observações meteorológicas obtidas no ambiente protegido cultivado com a cultura do tomate foram feitas com sensores acoplados a um sistema automático de aquisição de dados, modelo CR10X da Campbell Scientific, programado para fazer medições a cada dez segundos e armazenar dados a cada dez minutos, instalado no centro da área cultivada. Os modelos obtidos foram avaliados com base nos índices de concordância de Wilmont (1985) e coeficiente linear e angular de determinação da regressão para a comparação entre os valores.

O coeficiente de determinação permite verificar qual a concordância entre os métodos. Para escolha de uma equação que possa representar a área foliar em função das dimensões foliares, procedeu-se aos estudos de regressão utilizando-se uma equação linear.

\section{Resultados E Discussão}

Pela Figura 1 é possível observar a evolução da área foliar ao longo do ciclo da cultura. A equação que melhor se ajustou aos dados foi $Y=-1301,3+0,17965 x-0,0013 x^{2}$, com $R^{2}=0,9877$. O crescimento se deu até os 50 dias; daí se observa, então, um declínio, que ocorre até o final do ciclo. O crescimento inicial lento ocorre em virtude, provavelmente, das plantas gastarem grande parte da energia para fixação no solo visto que, nesta fase, as raízes são o dreno preferencial dos fotoassimilados; Fayad et al. (2001), verificaram comportamento semelhante para o híbrido EF-50, com o declínio na área foliar a partir dos 93 DAT e observaram, para a cv. Santa Clara, que o declínio ocorreu a partir dos 58 DAT.

Observa-se, na Figura 2, a relação entre o Índice de área foliar (IAF) e dias após o transplantio (DAT). Verifica-se que o IAF atingiu seu valor máximo de 2,82 aos 70 DAT e começou a diminuir chegando a 2,7 e 2,0, respectivamente, aos 80 e 100 dias após o transplantio. Este decréscimo está relacionado com a 


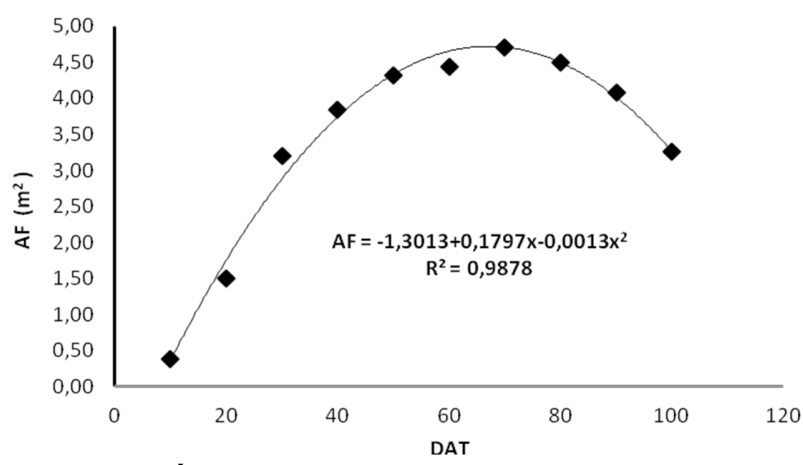

Figura 1. Área Foliar (AF) em função dos dias após transplantio (DAT) da cultura do tomate, em condições de ambiente protegido

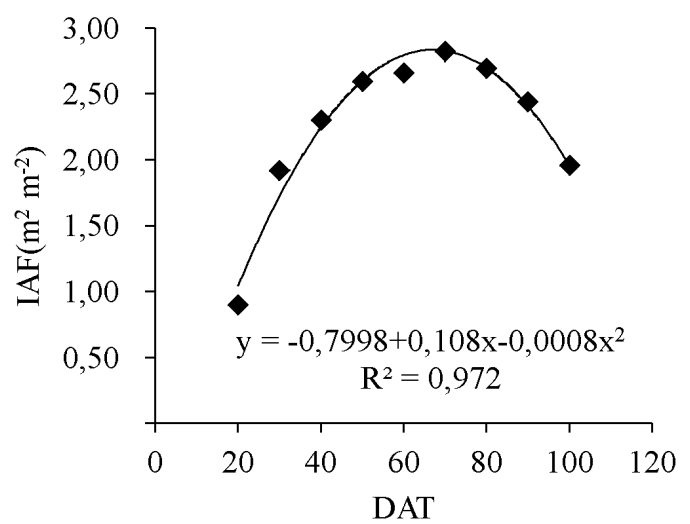

Figura 2. Índice de área foliar (IAF) em função dos dias após o transplantio (DAT) da cultura do tomate, em condições de ambiente protegido

abscisão das folhas velhas. O valor de pico de IAF do tomateiro em estufa encontrado por Fayad et al. (2001) foi de 4,12.

O IAF condiciona a interceptação da radiação solar cuja otimização é fundamental para maximizar a produção de cachos e de frutos (dreno), os quais determinam a produtividade da cultura do tomateiro.

A partir do modelo apresentado pode-se determinar o valor do IAF (Figura 2) a partir da DAT, o máximo de produtividade (Figura 3) e o período em que este máximo irá ocorrer, contribuindo para auxiliar na escolha da melhor época de semeadura e transplante da cultura em função da condição em que se irá cultivar e do período do ano, uma vez que se conhece

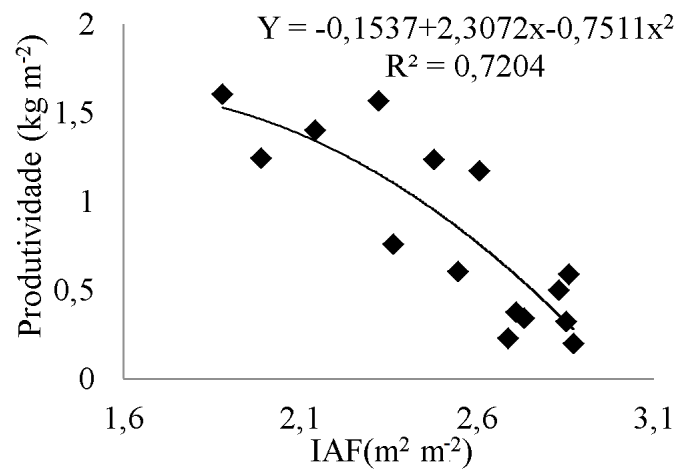

Figura 3. Produtividade média da cultura do tomate em função do índice de área foliar (IAF) em ambiente protegido o momento de maior capacidade de consumo de luz e energia. Nas condições em que o experimento foi desenvolvido, o IAF máximo ocorreu em $70 \mathrm{DAP}$ com valor de $2,8 \mathrm{~m}^{2} \mathrm{~m}^{-2}$; portanto, obtém-se, aplicando o modelo obtido para condição de ambiente protegido, uma produtividade máxima de $0,448 \mathrm{~kg} \mathrm{~m}^{-2}$.

Observa-se, na Figura 4, que a colheita de frutos teve início 68 dias após o transplantio (DAT) e que a produtividade da cultura foi crescente até os 101 DAT, momento em que os frutos já não apresentaram tamanho considerado comercial, isto é, acima de $80 \mathrm{~g}$, segundo a classificação de Ortega-Farias et al. (2004).

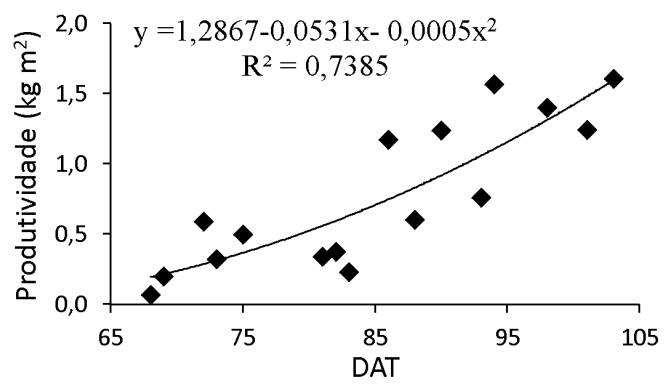

Figura 4. Produtividade média semanal da cultura do tomate em condições de ambiente protegido

Na Tabela 1 estão os componentes de produção da cultura do tomate em condições de ambiente protegido, ao final do ciclo da cultura, que foram de 21,5 frutos por planta, pesando 158 $\mathrm{g}$ em média. Os valores obtidos nesta pesquisa foram maiores que os encontrados por Carrijo et al. (2004) cujo resultado foi de $119 \mathrm{~g}$ (peso médio dos frutos) e para a produtividade (7,62 $\mathrm{kg} \mathrm{m}^{-2}$ ) e por Fernandes et al. (2002) para o peso do fruto do híbrido Carmen, com apenas um cacho $\left(154,66 \mathrm{~g}\right.$ fruto $\left.^{-1}\right)$. Loss et al. (2009) encontraram, estudando os efeitos da enxertia na produção e qualidade de tomateiros cultivados em ambiente protegido, para os cultivares Santa Clara e Débora, 70,40 e $76,78 \mathrm{t} \mathrm{ha}^{-1}$, respectivamente. Tamiso (2005) concluiu, em estudos com 11 cultivares, que o maior desempenho atingiu 2,1777 e 1,870,6 kg planta ${ }^{-1}$, respectivamente, para as cultivares Sahel e Colibri.

Tabela 1. Valores médios de número de frutos por planta, perímetro do fruto, peso do fruto e produtividade da cultua do tomate, em condições de ambiente protegido

\begin{tabular}{|c|c|c|c|c|}
\hline \multirow{2}{*}{$\begin{array}{l}N^{\circ} \text { de frutos } \\
\text { por planta }\end{array}$} & \multicolumn{2}{|c|}{ Perímetro (cm) } & \multirow{2}{*}{$\begin{array}{l}\text { Peso do } \\
\text { fruto }(\mathrm{g})\end{array}$} & \multirow{2}{*}{$\begin{array}{c}\text { Produtividade } \\
\text { (t ha-1) }\end{array}$} \\
\hline & maior & m & & \\
\hline 21,5 & 22,83 & 22,10 & 158,14 & 123 \\
\hline
\end{tabular}

Os valore s de produtividade deste trabalho foram inferiores aos encontrados por Cardoso (2007) que obteve uma produção do tomateiro com um ou dois cachos do híbrido Rebeca apresentando a menor produtividade por área $\left(5,84 \mathrm{~kg} \mathrm{~m}^{-2}\right)$ com 5,5 plantas $\mathrm{m}^{-2} \mathrm{em} 119$ DAT e a maior $\left(22,61 \mathrm{~kg} \mathrm{~m}^{-2}\right)$, com 11,1 plantas $\mathrm{m}^{-2} \mathrm{em} 134$ DAT; entretanto, Camargos et al. (2000) obtiveram, com o híbrido Carmen, maior produtividade comercial, $136 \mathrm{t} \mathrm{ha}^{-1}$.

Os parâmetros meteorológicos monitorados durante a pesquisa se encontram na Tabela 2. A temperatura média no interior do ambiente protegido foi $7,2 \%$ maior que a temperatura 
fora da estufa; apesar disto, os valores de radiação solar global, saldo de radiação, velocidade do vento e umidade relativa do ar, apresentaram valores inferiores aos observados fora da estufa. A velocidade média do vento na casa de vegetação foi $23,3 \%$ menor que aquela ocorrida externamente.

Tabela 2. Média das variáveis microclimáticas: temperatura do ar a $2 \mathrm{~m}(\mathrm{~T})$, radiação global $(\mathrm{Rg})$, saldo de radiação $(R n)$, velocidade do vento $(V \vee)$ e umidade relativa do ar (UR), observadas no interior e fora do ambiente protegido, durante todo o ciclo do tomateiro

\begin{tabular}{|c|c|c|c|c|c|}
\hline \multirow{2}{*}{ Períodos } & $\bar{T}$ & $\mathbf{R g}$ & $\mathbf{R n}$ & Vv & UR \\
\hline & ${ }^{\circ} \mathrm{C}$ & \multicolumn{2}{|c|}{ MJ $\mathrm{m}^{-2}$} & $\mathrm{~m} \mathrm{~s}^{-1}$ & $\%$ \\
\hline & \multicolumn{5}{|c|}{ Estufa plástica } \\
\hline Noturno & 22,0 & . & 0,00 & 0,46 & 93,2 \\
\hline \multirow[t]{2}{*}{ Diurno } & 25,9 & 10,78 & 6,68 & 0,71 & 73,3 \\
\hline & \multicolumn{5}{|c|}{ Campo } \\
\hline Noturno & 20,4 & - & 0,00 & 1,2 & 94,5 \\
\hline Diurno & 24,6 & 17,00 & 11,40 & 3,3 & 78,7 \\
\hline
\end{tabular}

Observa-se que na Figura 5 os valores de radiação global durante o ciclo da cultura nem sempre estiveram acima de 8 $\mathrm{MJ} \mathrm{m}^{-2}$ valor considerado ideal. O aumento da irradiância pode elevar a produção de fotoassimilados e sua disponibilidade para o crescimento da planta e produção de frutos mesmo que o crescimento e o desenvolvimento normal das culturas só ocorrem quando a quantidade de radiação recebida for superior ao limite trófico. Para a maioria das hortaliças, como o tomateiro, esse nível é de aproximadamente $8,4 \mathrm{MJ} \mathrm{m}^{-2} \mathrm{~d}^{-1}$, considerado como nível em que a planta produz o mínimo de fotoassimilados necessários à sua manutenção (Beckmann et al., 2006).

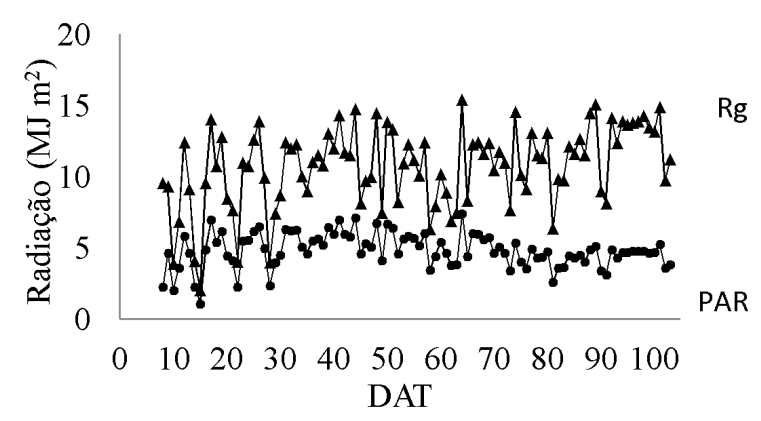

Figura 5. Radiação solar global $(\mathrm{Rg})$ e radiação fotossinteticamente ativa (PAR) no interior do ambiente protegido em função dos dias após transplantio (DAT) do tomateiro

Apenas 5\% da energia total que incide na superfície terrestre são aproveitados pelas plantas para a formação de carboidratos; o restante é emitido em comprimentos de ondas maiores, que é perdido na forma de calor e refletido (Taiz \& Zeiger, 2004). Verifica-se, então, que $1,3 \%$ da radiação incidente ao topo da atmosfera é utilizado pelas plantas para a fotossíntese. Righi \& Bernardes (2008) afirmam que a área foliar e o índice de área foliar (IAF) são parâmetros determinantes da produtividade.

Kunz et al. (2007) observaram, avaliando o rendimento, a eficiência de interceptação e de uso da radiação fotossinteticamente ativa pela cultura do milho, que o aumento da eficiência de interceptação de PAR foi acompanhado de um aumento do IAF da cultura até 50 a 60 dias após a emergência, quando ocorreu o IAF máximo.

Os valores de radiação fotossinteticamente ativa (PAR) no interior do ambiente protegido representam, em média, 45\% da radiação solar global (Rg) (Figura 5). A radiação PAR é a energia contida na faixa de 400 a 700 $\mathrm{nm}$ do espectro de radiação. Esta energia é utilizada pelas plantas na realização dos processos de fotoconversão, fotooxidação e fotossíntese.

\section{Conclusões}

1. É possível determinar, em ambiente protegido, o índice de área foliar da cultura do tomate considerando-se os dias após o transplantio.

2. A cultura teve seu período de máxima produtividade a partir dos 85 dias após transplantio, período em que o índice de área foliar entrou em declínio.

\section{Literatura Citada}

Andriolo, J. L. Fisiologia da produção de hortaliças em ambiente protegido. Horticultura Brasileira, v.18, p.26-33, 2000.

Andriolo, J. L.; Ross, T. D.; Witter, M. Crescimento, desenvolvimento e produtividade do tomateiro cultivado em substrato com três concentrações de nitrogênio na solução nutritiva. Ciência Rural, v.34, p.1451-1457, 2004.

Astegiano, E. D.; Favaro J. C; Bouzo, C. A. Estimación del área foliar em distintos cultivares de tomate (Lycopersicon esculentum Mill.) utilizando medidas foliares lineales. Investigation Agrícola, v.16, p.245-256, 2001.

Beckmann, M. Z.; Duarte, G. R. B.; Paula, V. A.; Mendez, M. E. G.; Peil, R. M. N. Radiação solar em ambiente protegido cultivado com tomateiro nas estações verão-outono do Rio Grande do Sul. Ciência Rural, v.36, p.86-92. 2006.

Caliman, F. R. B.; Silva, D. J. H.; Fontes, P. C. R.; Stringheta, P. C.; Moreira, G. R.; Cardoso, A. A. Avaliação de genótipos de tomateiro cultivados em ambiente protegido e em campo nas condições edafoclimáticas de Viçosa. Horticultura Brasileira, v.23, p.5068-5074, 2005.

Camargos, M. I.; Fontes, P. C. R.; Cardoso, A. A. Produção de tomate longa vida em estufa, influenciada por espaçamento e número de racimos por planta. Horticultura Brasileira, v.18, p.563-564, 2000.

Cardoso, F. B. Produtividade e qualidade de tomate com um e dois cachos em função da densidade de plantio, em hidroponia. Viçosa: UFV, 2007. 39p. Dissertação Mestrado

Carrijo, O. A.; Vidal, M. C.; Reis, N. V. B.; Souza, R. B.; Makisima, N. Produtividade do tomateiro em diferentes substratos e modelos de casas de vegetação. Horticultura Brasileira, v.22, p.5-9, 2004.

Carvalho, L. A.; Tessarioli Neto, J. Produtividade de tomate em ambiente protegido, em função do espaçamento e número de ramos por planta. Horticultura Brasileira, v.23, p.986$989,2005$. 
Costa, C. C.; Oliveira, C. D. de; Silva, C. J. da; Timossi, P. C.; Leite, I. C. Crescimento, produtividade e qualidade de raízes de rabanete cultivadas sob diferentes fontes e doses de adubos orgânicos. Horticultura Brasileira, v.24, p.118122, 2006.

EMBRAPA - Empresa Brasileira de Pesquisa Agropecuária. Centro Nacional de Pesquisa de Solos. Sistema brasileiro de classificação de solos: produção de informação. Rio de Janeiro: EMBRAPA, 1999. 412p.

Fageria, N. K.; Baligar, V. C.; Clark, R. B. Physiology of crop production. Binghamton: The Haworth Press, 2006. 345p.

FAO - Food and Agriculture Organization. Protected cultivation in the mediterrenean climate. Rome: FAO, 1990. 313p. paper, 90

Fayad, J. A.; Fontes, P. C. R.; Cardoso, A. A.; Finger, F. L.; Ferreira, F. A. Crescimento e produção do tomateiro cultivado sob condições de campo e ambiente protegido. Horticultura Brasileira, v.19, p.365-370. 2001.

Fernandes, A. A.; Martinez, H. E. P.; Fontes, P. C. R. Produtividade, qualidade dos frutos e estado nutricional do tomateiro tipo longa vida conduzido com um cacho, em cultivo hidropônico, em função das fontes de nutrientes. Horticultura Brasileira, v.20, p.564-570, 2002.

Gonzalez-Sanpedro, M. C.; Toan, T. le; Moreno, J.; Kergoat, L.; Rubio, E. Seasonal variations of leaf area index of agricultural fields retrieved from Landsat data. Remote Sensing of Environment, v.112, p.810-824, 2008.

Guimarães, M. A.; Silva. D. J. H.; Peternelli, L. A.; Fontes. P. C. R. Distribuição de fotoassimilados em tomateiro com e sem a retirada do primeiro cacho Bioscience Journal, v.25, p.83-92, 2009.

Kunz, J. H.; Bergonci, J. I.; Bergamaschi, H.; Dalmago, G. A.; Heckler, B. M. M.; Comiran, F. Uso da radiação solar pelo milho sob diferentes preparos do solo,espaçamento e disponibilidade hídrica. Pesquisa Agropecuária Brasileira, v.42, p.1511-1520, 2007.
Loos, R. A.; Caliman, F. R. B.; Silva, D. J. H. da. Enxertia, produção e qualidade de tomateiros cultivados em ambiente protegido, Ciência Rural, v.39, p.232-235, 2009.

Monte, J. A.; Pacheco, A. de S.; Carvalho, D. de F.; Pimentel, C. Influência do turno de rega no crescimento e produção do tomateiro no verão em Seropédica. Horticultura Brasileira, v.27, p.222-227, 2009.

Monteiro, J. E. B. A.; Sentelhas, P. C.; Chiavegato, E. J.; Guiselini, C.; Santiago, A. V.; Prela, A. Estimação da área foliar do algodoeiro por meio de dimensões e massa das folhas. Bragantia, v.64, p.15-24, 2005.

Ortega-Farías, S.; Calderon R.; Martelli, N.; Antonioletti, R. Evaluacion de un modelo para estimar la radiacion neta sobre um cultivo de tomate industrial. Agricultura Técnica, v.61, p.41-49, 2004.

Pereira, C.; Marchi, G.; Silva, E. C. Produção de tomate-caqui em Estufa. Série extensão. Lavras: UFLA, 2000. 26p.

Pôrto, D. R. de Q.; Negreiros, M. Z. de; Medeiros, J. F. de; Gondim, A. R. de O.; Bezerra Neto, F. Crescimento do melão 'Torreon' cultivado em diferentes coberturas de solo e lâminas de irrigação. Revista Caatinga, v.18, p.232-237, 2005.

Righi, C. A.; Bernardes, M. S. A. Disponibilidade de energia radiante em um sistema agroflorestal com seringueiras: Produtividade do feijoeiro, Bragantia, v.67, p.533-540, 2008.

Rocha, M. Q. Crescimento, fenologia e rendimento do tomateiro cereja em cultivo hidropônico. Pelotas: UFPel, 2009. 129p. Dissertação Mestrado

Souza, J. L. de; Nicácio, R. M.; Moura, M. A. L. Global solar radiation measurements in Maceió, Brazil. Renew Energy, v.30, p.1205-1220, 2005.

Taiz, L.; Zeiger, E. Fisiologia vegetal. 3.ed. Porto Alegre: Artmed. 2004. 719p.

Tamiso, L. G. Desempenho de cultivares de tomate (Lycopersicon esculentum Mill.) sob sistemas orgânicos em cultivo protegido. Piracicaba: ESALQ/USP, 2005. 87p. Dissertação Mestrado 